\title{
IL-17 produced by neutrophils regulates IFN- $\gamma$-mediated neutrophil migration in mouse kidney ischemia-reperfusion injury
}

\author{
Li Li,,1,2 Liping Huang,1,2 Amy L. Vergis,,1,2 Hong Ye,,1,2 Amandeep Bajwa,1,2 Vivek Narayan,,1,2 \\ Robert M. Strieter, ${ }^{1,2}$ Diane L. Rosin, ${ }^{2,3}$ and Mark D. Okusa1,2 \\ 1Department of Medicine, ${ }^{2}$ Center for Immunity, Inflammation, and Regenerative Medicine, and \\ ${ }^{3}$ Department of Pharmacology, University of Virginia, Charlottesville, Virginia, USA.
}

\begin{abstract}
The IL-23/IL-17 and IL-12/IFN- $\gamma$ cytokine pathways have a role in chronic autoimmunity, which is considered mainly a dysfunction of adaptive immunity. The extent to which they contribute to innate immunity is, however, unknown. We used a mouse model of acute kidney ischemia-reperfusion injury (IRI) to test the hypothesis that early production of IL-23 and IL-12 following IRI activates downstream IL-17 and IFN- $\gamma$ signaling pathways and promotes kidney inflammation. Deficiency in IL-23, IL-17A, or IL-17 receptor (IL-17R) and $\mathrm{mAb}$ neutralization of CXCR2, the 19 subunit of IL-23, or IL-17A attenuated neutrophil infiltration in acute kidney IRI in mice. We further demonstrate that IL-17A produced by GR-1 ${ }^{+}$neutrophils was critical for kidney IRI in mice. Activation of the IL-12/IFN- $\gamma$ pathway and NKT cells by administering $\alpha$-galactosylceramide-primed bone marrow-derived DCs increased IFN- $\gamma$ production following moderate IRI in WT mice but did not exacerbate injury or enhance IFN- $\gamma$ production in either $I l 17 a^{-/}$or $I l 17 r^{-/}$mice, which suggested that IL-17 signaling was proximal to IFN- $\gamma$ signaling. This was confirmed by the finding that IFN- $\gamma$ administration reversed the protection seen in $I l 17 \mathrm{a}^{-/-}$mice subjected to IRI, whereas IL-17A failed to reverse protection in Ifng $\mathrm{g}^{-/-}$mice. These results demonstrate that the innate immune component of kidney IRI requires dual activation of the IL-12/IFN- $\gamma$ and IL-23/IL-17 signaling pathways and that neutrophil production of IL-17A is upstream of IL-12/IFN- $\gamma$. These mechanisms might contribute to reperfusion injury in other organs.
\end{abstract}

\section{Introduction}

The heterodimeric cytokines IL-12 and IL-23, which are secreted mainly by activated DCs and macrophages in response to TLR activation $(1,2)$, stimulate $\mathrm{T}$ cell differentiation and function in linking innate and adaptive immunity. IL-12 and IL-23 contribute to autoimmunity and host defense through separate IL-12/IFN- $\gamma$ and IL-23/IL-17-dependent pathways (3). IL-23 is composed of p40 and p19 subunits, whereas bioactive 70-kDa IL-12 (IL-12p70) is a $\mathrm{p} 35 / \mathrm{p} 40$ heterodimer. Although IL-23 and IL-12 share the $\mathrm{p} 40$ subunit and some similar functions, they possess distinct features (4). IL-12 induces the production of IFN- $\gamma$ by NK/NKT cells and Th1 cells, while IL-23, in conjunction with IL- 6 and TGF- $\beta$, stimulates the differentiation of Th17 cells (the subset of T helper cells that produce IL-17) and the subsequent production of IL-17 (5). p40/p19 induces Th17 cells to produce IL-17, a pro-inflammatory cytokine that plays an important role in host defense and mediates chronic inflammation and autoimmune diseases, such as rheumatoid arthritis, multiple sclerosis, inflammatory bowel disease, and psoriasis (6-9) in both humans and mice. IL-23 and IL-17 are critical mediators for neutrophil recruitment and migration through the induction of granulopoiesis and production of G-CSF, IL-6, IL-1 $\beta$, TNF- $\alpha$, and neutrophil chemoattractant chemokines, including CXCL1, -2, and -5 (10-12).

Although most data support a role of the IL-23/Th17/IL-17 pathway in mediating chronic inflammatory diseases (3), such as rheumatoid arthritis, asthma, systemic lupus erythematosus, multiple sclerosis, and allograft rejection (13-15), some data suggest

Conflict of interest: The authors have declared that no conflict of interest exists. Citation for this article: J. Clin. Invest. 120:331-342 (2010). doi:10.1172/JCI38702. that the IL-23/Th17/IL-17 pathway might participate in innate immunity. Acute infections lead to activation of DCs to produce IL-23 with subsequent activation of IFN- $\alpha / \beta$ and IFN- $\gamma / \delta$ and NKT cell production of IL-17 (3, 10, 16-18), which leads to the recruitment of neutrophils to sites of infection (13).

In kidney ischemia-reperfusion injury (IRI), a model of acute kidney injury, IL-12/IFN- $\gamma$ and IL-23/IL-17 pathways appear to be activated. Ischemic kidney injury causes production of IL-17-promoting cytokines, such as TGF- $\beta$, IL- 6 , TNF- $\alpha$, and IL- $1 \beta$, in the inflamed kidney (19). In addition, we and others have shown that IFN- $\gamma$-producing CD $4^{+} \mathrm{T}$ cells, NKT cells, and GR- $1^{+}$neutrophils are important in the pathogenesis of kidney IRI $(20,21)$. However, very few studies have examined the role of IL-12/IFN- $\gamma$ or IL-23/IL-17 or their interaction in the innate immune response to injury. We sought to test the early involvement of IL-23/IL-17 in innate immunity and the interaction of IL-17A and IFN- $\gamma$ in kidney IRI innate immunity. Our studies demonstrated that both IL-12/IFN- $\gamma$ and IL-23/IL-17 pathways are activated in kidney IRI and that IL-17A-producing neutrophils acted proximally and are required for IFN- $\gamma$ production and kidney injury following IRI.

\section{Results}

The IL-23/IL-17 axis is essential for the inflammatory response to kidney IRI. During the period of reperfusion following an ischemic event in kidney as well as numerous other organs, activation of the inflammatory system accompanies a complex immune cascade in response to ischemic injury. Increases in cytokines and chemokines mediate the influx of immune cells into kidney after injury. To test the involvement of the IL-23 cytokine pathway in injured kidneys, we initially investigated mRNA expression levels of the 2 subunits of IL-23, p40 
A
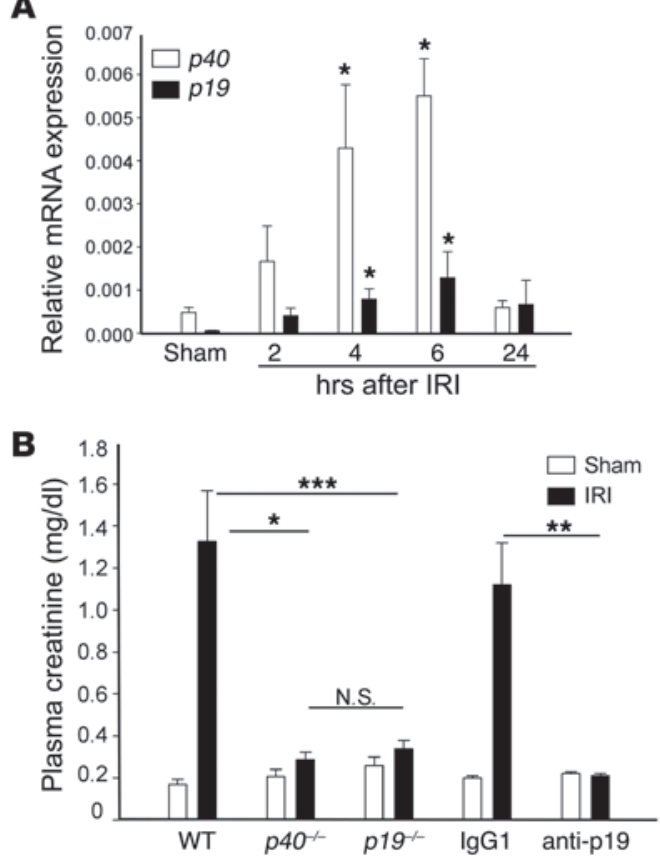

C

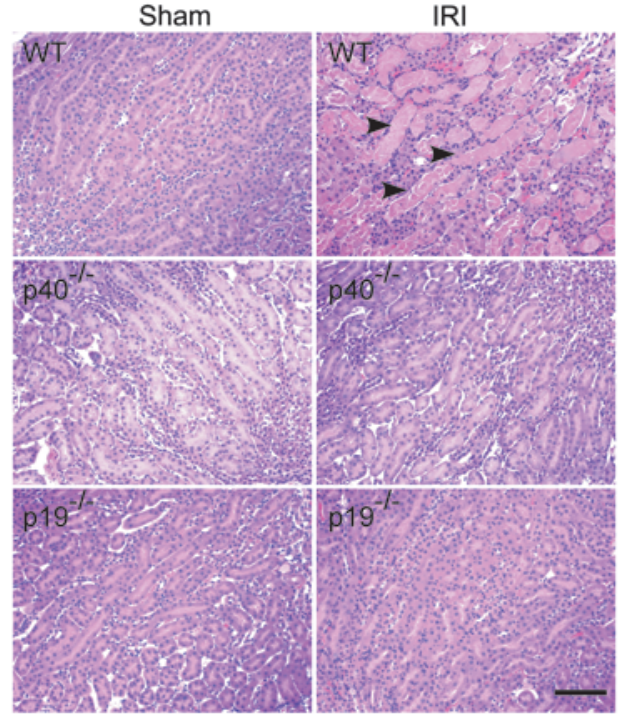

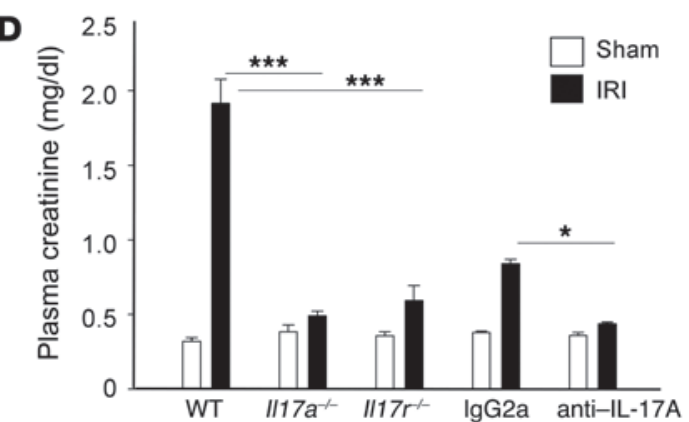

$\mathbf{E}$

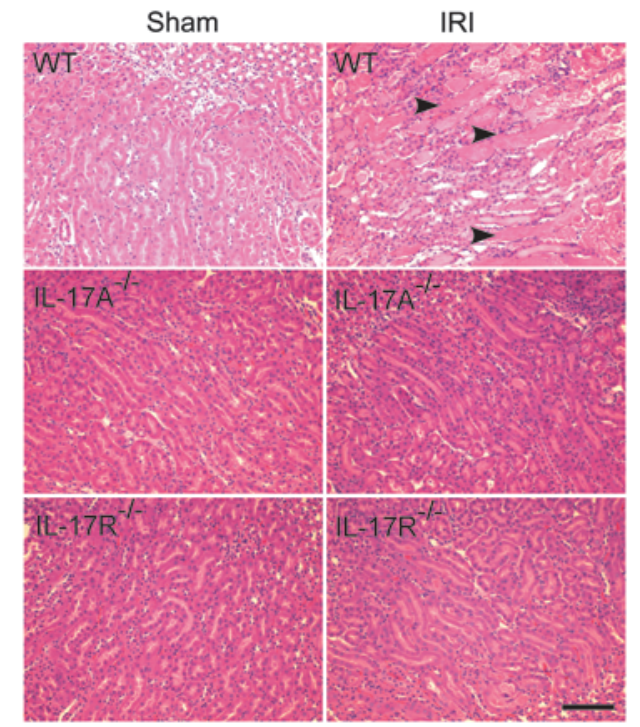

\section{Figure 1}

The IL-23/IL-17 pathway contributes to kidney IRI. (A) mRNA levels of $p 40$ and $p 19$ were measured by real-time PCR in kidneys after 28 minutes of ischemia and exposure to different times of reperfusion. Values are expressed as relative gene expression (compared with GAPDH) in shamoperated samples and IRI samples following different times of reperfusion. $n=3-5$. ${ }^{*} P<0.05$ compared with sham. (B) Plasma creatinine was measured as an indication of kidney function in mice exposed to sham operation or IRI (ischemia followed by 24 hours of reperfusion). IgG1, WT mice that received $100 \mu \mathrm{g} \mathrm{IgG1}$ isotype control 18 hours prior to kidney IRI; anti-p19, WT mice that received anti-p19 mAb treatment 18 hours prior to kidney IRI. $n=4-18 ;{ }^{*} P<0.05 ;{ }^{*} P<0.01$; ${ }^{* \star *} P<0.001$. (C) Representative morphology (by H\&E staining) of kidney outer medulla from WT, $p 40^{---}$, and $p 19^{-/-}$sham and IRI mice. (D) Plasma creatinine in WT, $I / 17 r^{--}$, and $I / 17 a^{-/-}$, IgG2a, and anti-IL-17A sham and IRI mice after 24 hours of reperfusion. $n=4-9 ;{ }^{\star} P<0.05 ;^{* \star *} P<0.001$. (E) H\&E staining of kidney outer medulla from WT, $I / 17 r^{-1}$, and $I / 17 a^{-/-}$sham and IRI mice after 24 hours of reperfusion. In $\mathbf{C}$ and $\mathbf{E}$, arrowheads indicate necrotic tubules. Scale bars: $100 \mu \mathrm{m}$. Values are mean \pm SEM.

and p19, in kidney by real-time PCR at different reperfusion times following kidney ischemia and sham operation (control). As shown in Figure 1A, both $p 40$ and $p 19$ mRNA expression increased significantly between 4 and 6 hours after IRI compared with sham-operated control mice. We then compared kidney function and pathology after IRI in $p 40^{--}, p 19^{--}$, and WT mice. Following 24 hours of reperfusion, there was a marked increase in plasma creatinine in WT mice, but $p 40^{--}$and $p 19^{-/-}$mice were protected from kidney injury as indicated by lower plasma creatinine levels (Figure 1B), less tubular necrosis (Figure 1C), and lower acute tubular necrosis (ATN) scores (Supplemental Table 1; supplemental material available online with this article; doi:10.1172/JCI38702DS1). The protective effect 
$\mathbf{A}$

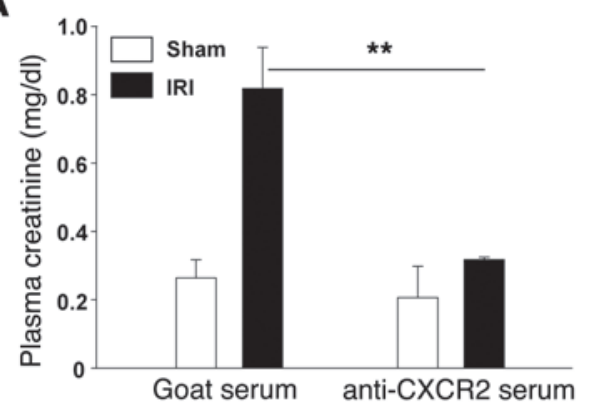

B

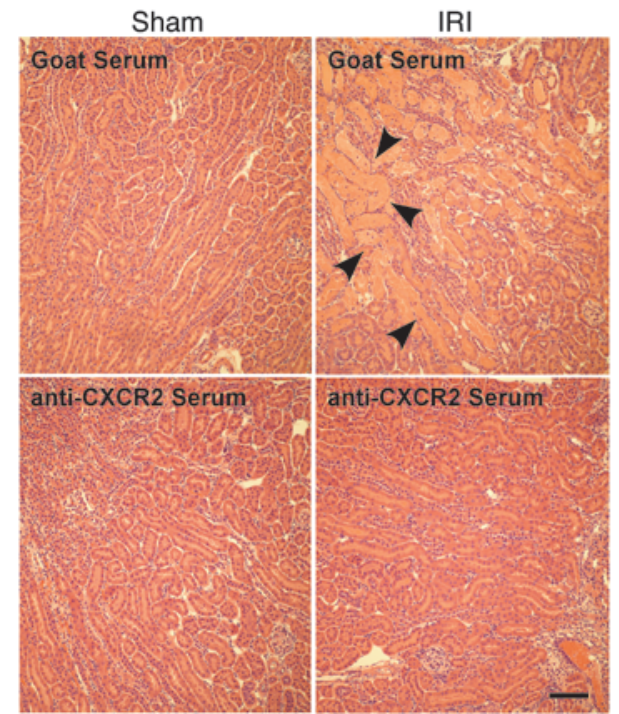

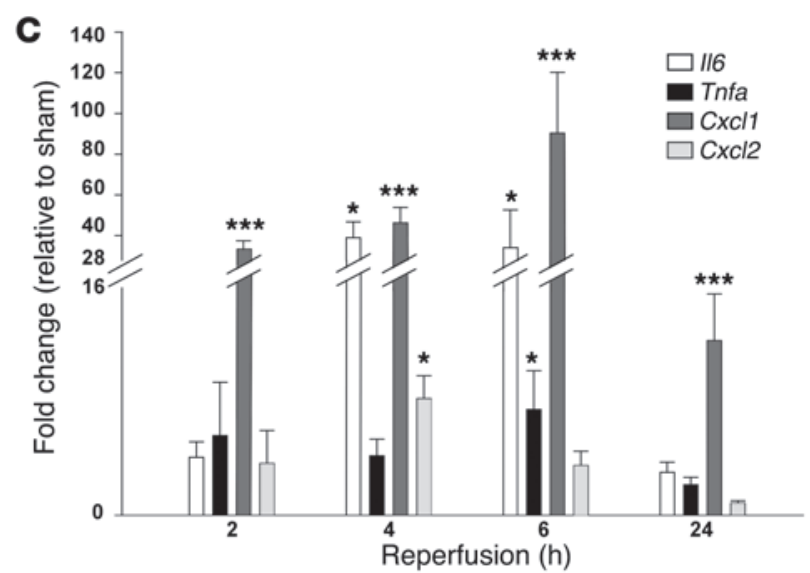

D

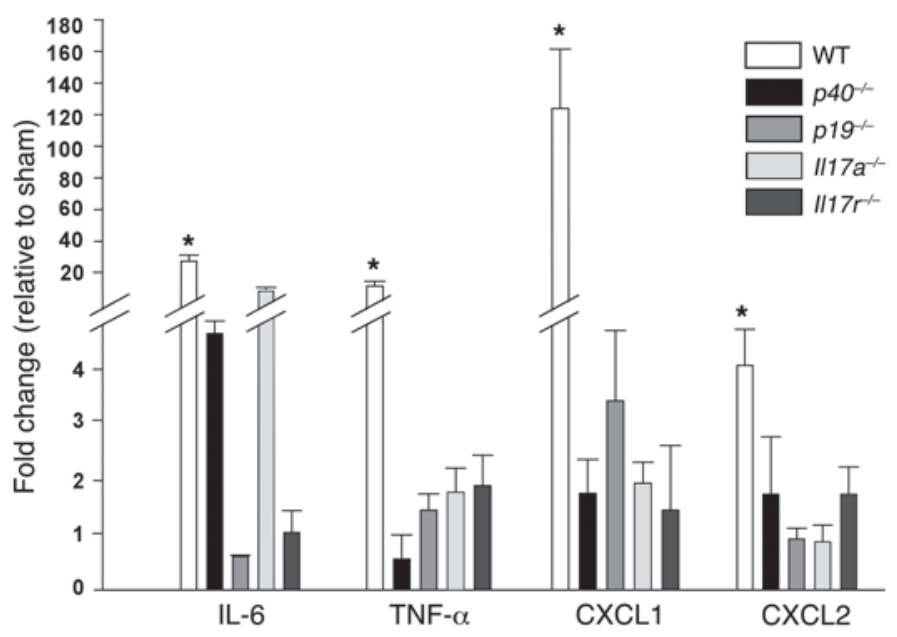

Figure 2

Activation of the IL-23/IL-17A/IL-17R pathway following kidney IRI increases kidney expression of proinflammatory cytokines and chemokines that mediate neutrophil recruitment. (A and B) Blocking CXCR2 attenuated kidney IRI inflammation. (A) Plasma creatinine levels in WT mice that received anti-CXCR2 goat serum or goat serum control 18 hours and 1 hour prior to sham or IRI. $n=4-6$; ${ }^{* *} P<0.01$. (B) Kidney morphology evaluated by H\&E staining. Arrowheads indicate tubular injury. Scale bar: $10 \mu \mathrm{m}$. (C and D) Kidney mRNA expression level (C) of IL-23/IL-17 downstream cytokines (Tfna and //6) and neutrophil chemoattractant chemokines (Cxc/1 and Cxc/2) was measured by real-time PCR at different time points following kidney reperfusion $\left(2,4,6\right.$, and 24 hours; $n=2-5$. ${ }^{*} P<0.05$; ${ }^{* *} P<0.001$ compared with sham) and (D) in WT, $p 40^{-/-}$, $p 19^{-/-}, I 117 a^{-/-}$, and $/ 117 r^{-1-}$ mice after 6 hours of kidney reperfusion $\left(n=2-8\right.$; ${ }^{\star} P<0.05$ compared with KO mice). Values are mean \pm SEM.

observed in $19^{-/-}$mice was also found when WT mice were pretreated with anti-p19 neutralization mAb $(100 \mu \mathrm{g}) 18$ hours prior to IRI compared with isotype IgG1-treated mice (Figure 1B). IL-23 promotes the production of IL-17A, a member of a family of cytokines whose downstream mediators regulate neutrophil recruitment and function. We hypothesized that increased IL-23 expression drives the production of IL-17A to promote kidney injury through its receptor, IL-17R, following ischemia-reperfusion. The protective effects observed in kidney function and morphology in $\mathrm{Il}_{17 \mathrm{a}^{-/} \text {and }}$ $I l 17 r^{-1}$ mice after IRI compared with WT mice demonstrated that the IL-17 signaling pathway was involved in kidney IRI (Figure 1, $\mathrm{D}$ and $\mathrm{E}$ ). Protection was also observed in WT mice pretreated with neutralization anti-IL-17A mAb (Figure 1D).

Downstream pro-inflammatory cytokines and chemokines associated with the IL-23/IL-17 pathway mediate neutrophil recruitment in kidney IRI. Infiltration of neutrophils is one of the hallmarks of kidney IRI and may be mediated by production of downstream pro-inflammatory cytokines/chemokines of the IL-23/IL-17 pathway. Blocking neutrophil infiltration by using an anti-CXCR 2 antibody prevented the increase in plasma creatinine levels and tubular necrosis in the kidney outer medulla following kidney IRI (Figure 2, A and B). Following kidney IRI, expression of the pro-inflammatory cytokines IL- 6 and TNF- $\alpha$ was elevated in kidneys as early as 2 hours following reperfusion and increased at 4-6 hours (Figure 2C). Expression of CXCL1 and CXCL2, chemokines known to mediate neutrophil migration, increased compared with sham at 2 and 4 hours after reperfusion, respectively. CXCL1 remained elevated 24 hours following reperfusion (Figure 2C). No significant change in Cxcl5 mRNA expression was identified in the reperfused kidneys compared with sham (data not shown). The rise in neutrophil chemotactic factors preceded the known time course (22) for neutrophil infiltration into kidneys following IRI. To investigate the 


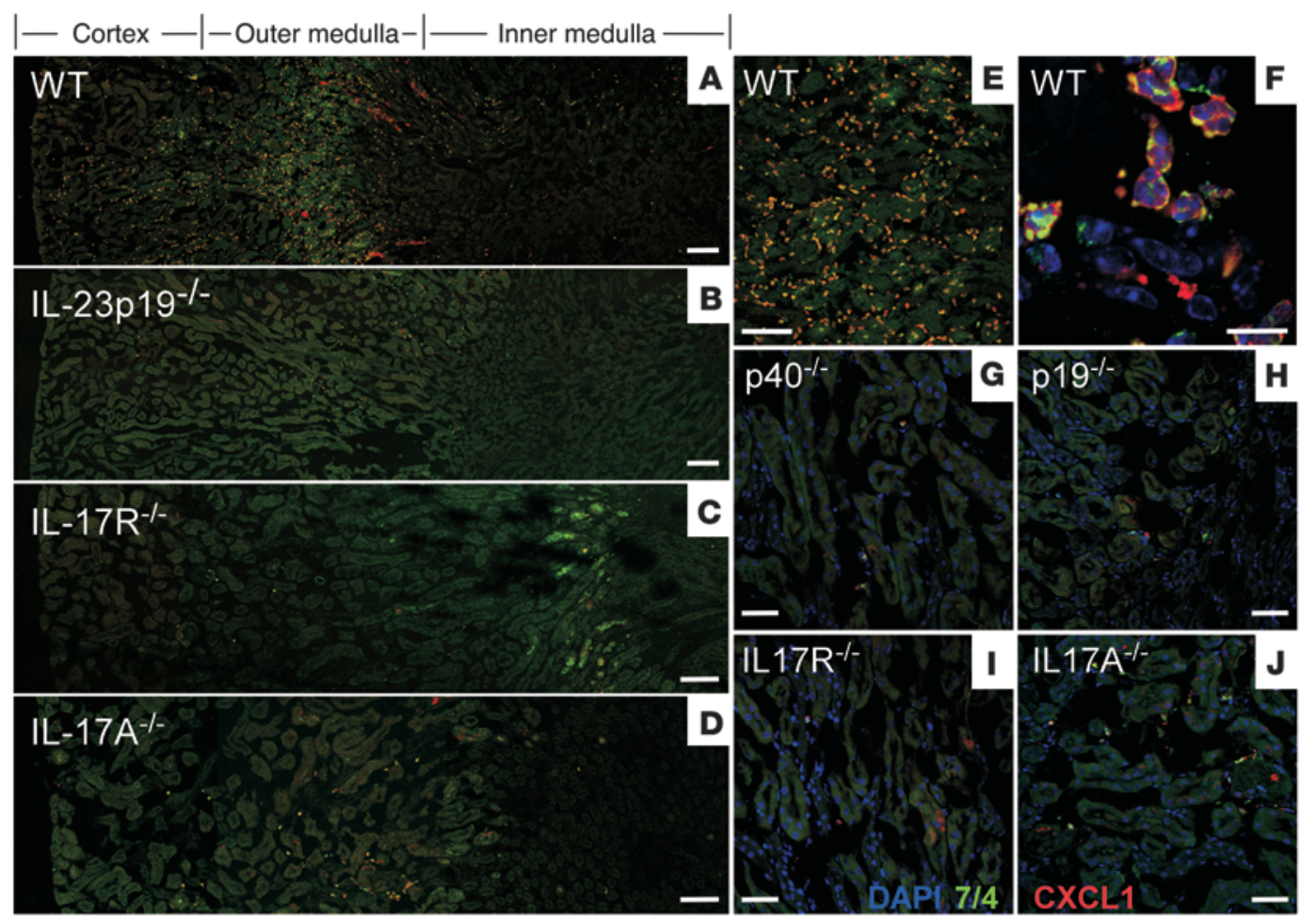

Figure 3

Immunofluorescent labeling demonstrates recruitment of 7/4+ neutrophils and CXCL1 expression in kidneys following IRI. (A-D) Panoramic views of kidney through the entire extent of cortex (lateral, left) and medulla (medial, right) were generated by stitching together 4 overlapping images (Adobe Photoshop). Labels at the top delineating approximate boundaries of cortex and inner and outer medulla apply to $\mathbf{A}$ and $\mathbf{B}$ (C and $\mathbf{D}$ are at a slightly higher magnification). (A) A large influx of $7 / 4^{+}$neutrophils (FITC epifluorescence; green) was seen in the kidney outer medulla 24 hours after IRI in WT mice. Some CXCL1 immunoreactivity (Cy3 epifluorescence; red) was evident in medullary tubule cells, but most was associated with infiltrating neutrophils. (B-D) Significantly less neutrophil recruitment and CXCL1 expression were observed in $p 199^{-1-}$, $1 / 17 r^{-1-}$, and $/ / 17 a^{-1-} \mid \mathrm{RI}$ mouse kidneys. (E-J) Higher magnification of images shows substantial neutrophil infiltration and colocalization (yellow) of CXCL1 and 7/4 immunoreactivity in neutrophils in medulla of WT IRI kidney (E and F) but not in kidneys from the KO mice that were protected from injury (G-J). Nuclei were labeled with DAPI (blue). Scale bars: $100 \mu \mathrm{m}(\mathbf{A}-\mathbf{D}) ; 10 \mu \mathrm{m}(\mathbf{F}) ; 40 \mu \mathrm{m}(\mathbf{E}, \mathbf{G}-\mathbf{J})$.

role of the IL-23/IL-17 axis in mediating cytokine and chemokine production following kidney IRI, Il6, Il1b, Tnfa, Cxcl1, and Cxcl2 mRNA levels were measured by real-time PCR in WT and $\mathrm{KO}$ mice after 6 hours of reperfusion. The increase in expression of IL-6, TNF- $\alpha$, CXCL1, and CXCL2 observed in WT mouse kidneys after

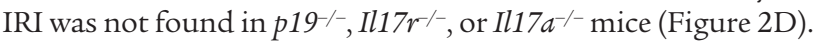

The observed effects on cytokine and chemokine production prompted us to evaluate a role of the IL-23/IL-17 pathway in neutrophil infiltration after IRI. The marked increase in infiltration of CD $11 \mathrm{~b}^{+} \mathrm{GR}-1^{+}$neutrophils in kidneys of WT mice after IRI was diminished in $p 40^{-/-}, p 19^{-/-}, I l 17 r^{-/}$, and $I l 17 a^{-/-}$mouse kidneys after IRI, as revealed by FACS analysis (Supplemental Figure 1). Immunofluorescence showed CXCL1 production mainly in kidney tubule cells at 6 hours following reperfusion (data not shown), but intense labeling for CXCL1 was observed in infiltrating $7 / 4^{+}$ neutrophils in kidneys of WT mice 24 hours after IRI (Figure 3, A, $\mathrm{E}$, and F), primarily in the outer medulla. A decrease in neutrophil

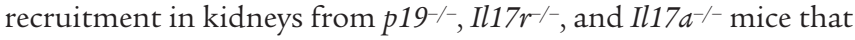
were protected from IRI was associated with low CXCL1 (Figure 3, B-D and G-J) and CXCL2 expression (data not shown). Collectively, these data strongly support the causal relationship between IL-23/IL-17 in neutrophil recruitment and the inflammatory immune response in kidneys after IRI.
Neutrophils are the major source of IL-17A in kidneys following IRI. We next performed a series of experiments to identify the cells in kidneys following IRI that produce IL-17A. After kidney ischemia and only 3 hours of reperfusion, by FACS analysis of intracellularly labeled cells, we found more IL-17A-producing CD $45^{+}$cells in IRI kidneys relative to sham (Figure 4A). $\mathrm{Il17}^{-/-} \rightarrow \mathrm{WT}$ and WT $\rightarrow$ WT bone marrow chimeras were created to examine the contribution of bone marrow-derived cells as the source of IL-17A in kidney IRI. Significant morphological (data not shown) and functional protection from kidney IRI was found in $I l 17 a^{-/-} \rightarrow$ WT IRI mice compared with $\mathrm{WT} \rightarrow$ WT mice. Plasma creatinine increased significantly in WT $\rightarrow$ WT mice after IRI, but not in $I l 17 \mathrm{a}^{-/-} \rightarrow$ WT IRI mice, which lacked IL-17A in bone marrow cells (Figure 4B). Similarly, fewer infiltrating neutrophils were found in kidneys of the protected chimeric mice by FACS analysis and immunostaining (data not shown). Therefore, we concluded that IL-17A-producing bone marrow-derived cells contribute to kidney injury. We then pretreated T cell- and B cell-deficient Rag $1^{-/-}$mice with anti-IL-17A mAb before IRI and found that they had a reduction in injury similar to that of WT mice pretreated with anti-IL-17A mAb (Figure 4C), with less 7/4+ neutrophil infiltration and neutrophil CXCL1 expression (Figure 4D) following kidney IRI. These in vivo studies suggested that cells other than T, B, and NKT cells produce IL-17A and are involved in kidney IRI. 
A

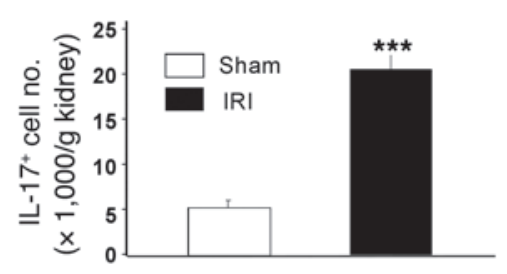

C

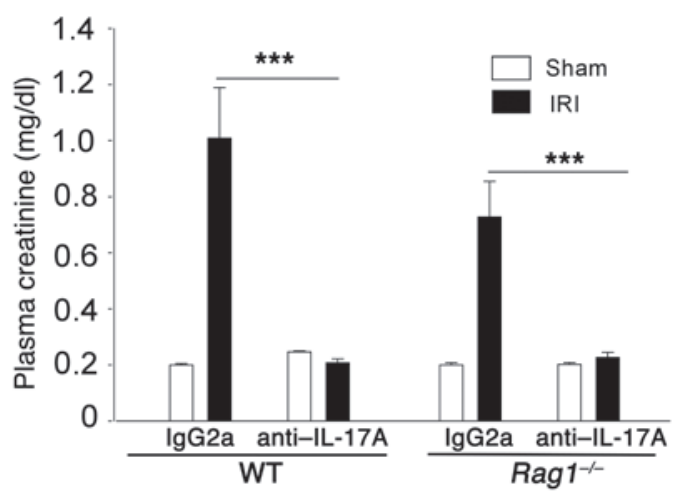

B

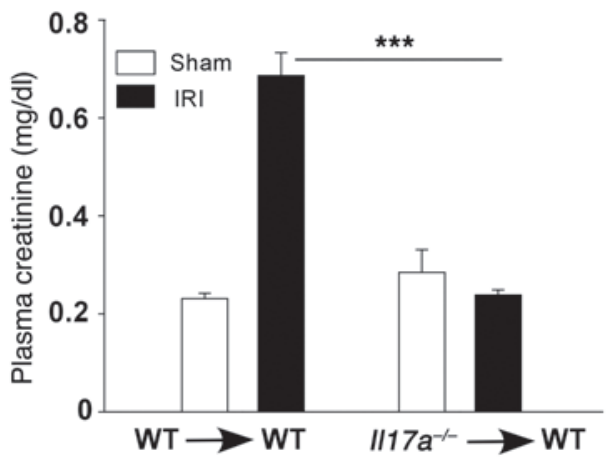

D

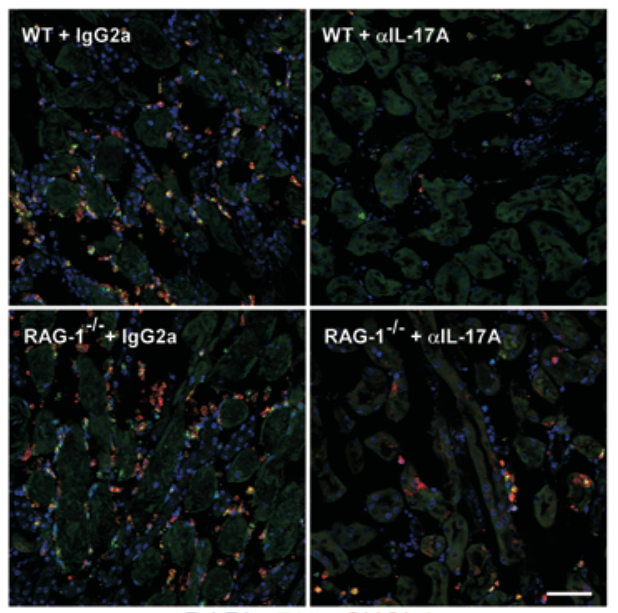

DAPI - $7 / 4$ - CXCL1

\section{Figure 4}

IL-17A produced from non-T and non-B bone marrow-derived cells contributes to kidney IRI. (A) Kidney CD45+ cells were isolated from sham and IRI mouse kidneys after 3 hours of reperfusion and restimulated in vitro as described in Methods. Intracellular IL-17A was measured by FACS, and the number of IL-17A-producing cells was evaluated with Caltag Counting Beads. $n=3$; ${ }^{* * *} P<0.001$. (B) Plasma creatinine in WT $\rightarrow$ WT and $I / 17 a^{-1-} \rightarrow$ WT chimeric mice 24 hours after kidney IRI. $n=4-7 ;{ }^{* * *} P<0.001$. (C) Plasma creatinine after kidney IRI in WT and Rag $1^{-/-}$mice that received anti-IL-17A mAb or IgG2a isotype control. $n=3-6$; ${ }^{* *} P<0.001$. (D) Recruitment of $7 / 4^{+}$cells (green) co-expressing CXCL1 (red) in kidney sections from WT and Rag1-/-IRI mice treated with isotype control (IgG2a) or anti-IL-17A neutralizing antibody. Nuclei were labeled with DAPI (blue). Scale bar: $50 \mu \mathrm{m}$. Values are mean \pm SEM.

To identify the leukocyte subset, we used an IL-17 secretion assay to simultaneously detect IL-17A-producing cells and their phenotype. Interestingly, IL-17A was secreted from the recruited neutrophils (Figure 5A) but not from CD4 or CD8 T cells or NK1.1 ${ }^{+}$ cells (Supplemental Figure 2). Finally, to demonstrate functional significance of IL-17 production by neutrophils in kidney IRI, we adoptively transferred to recipient $I l 17 a^{-/-}$mice neutrophils from the bone marrow of WT (WT $\rightarrow I l 17 a^{-/-}$mice) or $I l 17 a^{-/-}$mice $\left(\right.$ Il17 $a^{-/-} \rightarrow I_{117 a^{-/-}}$mice). Kidney injury was reconstituted in $\mathrm{WT} \rightarrow I l 17 a^{-/-}$but not $I l 17 a^{-/-} \rightarrow I l 17 a^{-/-}$mice (Figure 5B). Furthermore, in WT $\rightarrow I l 17 a^{-/-}$mice the reconstituted injury was blocked with $100 \mu \mathrm{g}$ anti-mouse IL-17A mAb. These data demonstrate that neutrophils, rather than T, NKT, or B cells, are the major source of IL-17A production involved in kidney IRI.

Impaired IFN- $\gamma$ production by GR-1 $1^{+}$neutrophils in mice with deficient IL-23/IL-17A/IL-17R pathways. We have shown previously that GR-1 ${ }^{+}$ neutrophils are the major immune source of IFN- $\gamma$ following kidney IRI (20) and in the current study we showed that IL-23/IL-17 is important for neutrophil recruitment following IRI. Therefore, we investigated whether disruption of the IL-23/IL-17 pathway alters the IFN- $\gamma$-mediated immune response to kidney IRI. As expected, fewer IFN- $\gamma$-producing GR- $1^{+}$neutrophils infiltrated the kidney after IRI in IL-12-deficient $\left(p 35^{-/-}\right)$mice than in WT mice, but this was also found in $p 40^{-/-}, p 19^{-/-}, I l 17 a^{-/-}$, and $I l 17 r^{-/}$mice (Table 1). Thus, blocking either the IL-23 or IL-17 pathway reduced not only neutrophil recruitment but also neutrophil IFN- $\gamma$ production, imparting an important role of the IL-17 pathway in IFN- $\gamma$-mediated kidney IRI.

Both IL-12/IFN- $\gamma$ and IL-23/IL-17 pathways are involved in activated NKT cell-mediated inflammation in kidney IRI. Previously we showed that CD1d-restricted NKT cell activation contributes critically to kidney IRI through IFN- $\gamma$ production and regulation of neutrophil infiltration (20). Here we further demonstrate the involvement of the IL-12/IFN- $\gamma$ pathway in IRI-induced kidney inflammation by using $p 35^{-/-}$and Ifng ${ }^{-/-}$mice. Compared with WT mice, ATN scores (Supplemental Table 1) and plasma creatinine levels (Figure 6A) were lower 24 hours after IRI in mice lacking p35 and IFN- $\gamma$ signaling, and plasma creatinine was significantly lower following kidney IRI in mice treated with neutralizing anti-IFN- $\gamma$ antibody (Figure 6A) compared with WT mice treated with IgG1 isotype control. In addition, following kidney IRI we observed an $81 \%$ reduction of $\mathrm{CD} 11 \mathrm{~b}^{+} \mathrm{GR}-1^{+}$neutrophils infiltrating the kidney both in mice 

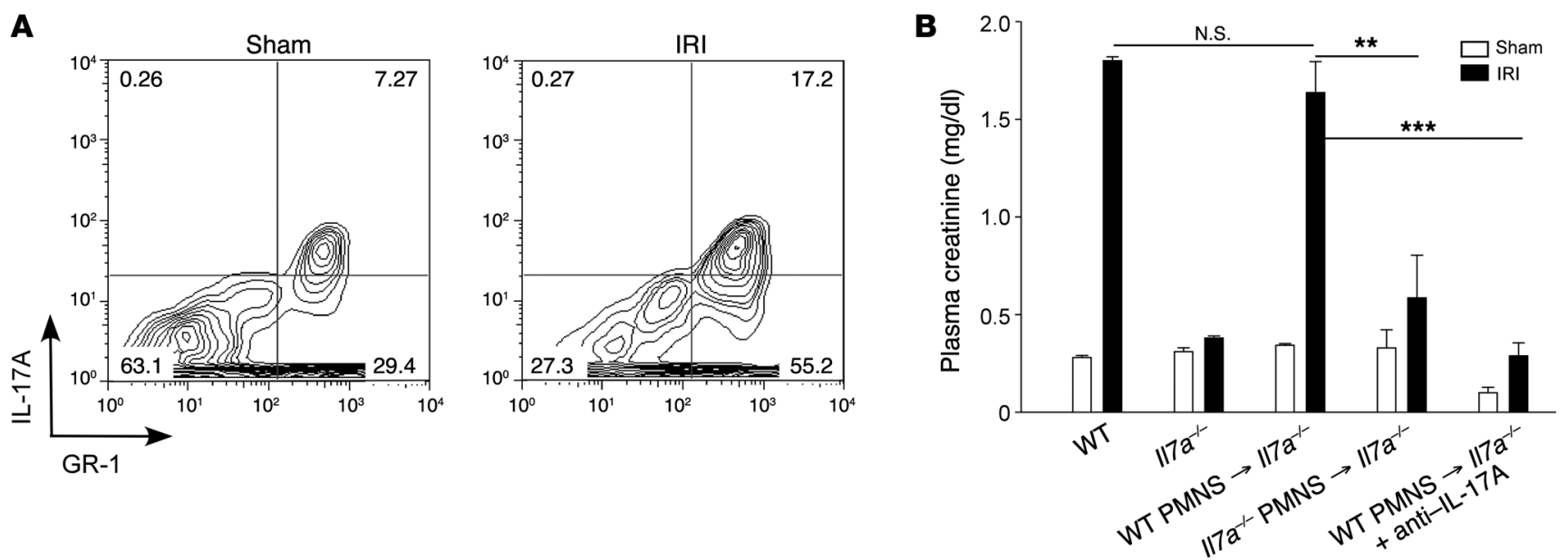

Figure 5

IL-17A produced by PMNs contributes to kidney IRI inflammation. (A) Identification of IL-17A-secreting cells in kidneys 3 hours after sham or IRI. Mouse kidney leukocytes were restimulated, and the secreted form of IL-17A was measured as described in Methods. IL-17A-secreting CD45+GR-1+7-AAD- cells were measured by FACS. The numbers within each box in the contour diagrams indicate the percentage of CD45+7-AAD- cells gated. (B) WT or $1 / 17 a^{-1-}$ PMNs were isolated from bone marrow and were adoptively transferred to $/ / 17 a^{-/-}$mice at the onset of kidney IRI, and in 1 group (WT $\rightarrow I / 17 a^{-/}+$anti-IL-17A) $100 \mu \mathrm{g}$ anti-IL-17A mAb was administered at the onset of IRI. Plasma creatinine was measured following 24 hours of kidney reperfusion. Values are mean \pm SEM. $n=4-7 ;{ }^{* \star} P<0.01 ;{ }^{* \star} P<0.001$.

lacking IFN- $\gamma(P<0.05 ; n=3-9)$ and in mice lacking p35 $(P<0.05$; $n=5-9)$ compared with WT IRI mice, thus indicating that the IL-12/IFN- $\gamma$ pathway is involved in neutrophil recruitment into kidney following IRI. Furthermore, IFN- $\gamma$ deficiency abrogated the IRI-induced increase in pro-inflammatory cytokine and chemokine mRNA expression (Supplemental Table 2). Therefore, we concluded that both the IL-12/IFN- $\gamma$ and IL-23/IL-17 pathways mediate neutrophil recruitment in kidney IRI.

Our results showing that both the IL-12/IFN- $\gamma$ and IL-23/IL-17 pathways mediate neutrophil recruitment in kidney IRI suggest that these pathways may also be important in NKT cell-mediated kidney injury. We posited that production of IL-12 and CD1d presentation of glycolipids by ischemia-reperfusion-activated DCs trigger and stimulate NKT cell-mediated kidney injury, and we further hypothesized that IL-23/IL-17 contributes to this process. To examine the interaction of NKT cells with IL-12/IFN- $\gamma$ and IL-23/IL-17 pathways in promoting the kidney inflammatory response, we used bone marrow-derived DCs (BMDCs) primed with $\alpha$-galactosylceramide (BMDC- $\alpha$ GalCer) to activate kidney NKT cells before a moderate (24-minute) subthreshold level of ischemic injury. This strategy has been used widely to modulate NKT cell activation in different mouse models and human disease, and substantial IFN- $\gamma$ production, which contributes to tissue injury and inflammation, has been found after administration of BMDC- $\alpha$ GalCer (23-28). Compared with WT mice that received unprimed BMDCs and showed no significant change in kidney function after a moderate ischemic injury, a large increase in the level of plasma creatinine was found in WT mice treated with BMDC- $\alpha$ GalCer (Figure 6B). However, creatinine was not elevated by BMDC- $\alpha$ GalCer and IRI in mice deficient in NKT cells $\left(\mathrm{Cd} 1 \mathrm{~d}^{-/-}\right.$and $\mathrm{Ja} 18^{-/-}$mice) or Ifng ${ }^{-/-}$(Figure 6B), but it was increased in Tnfa- ${ }^{-/-}$mice (1.55-fold \pm 0.12 -fold vs. 1.85 -fold \pm 0.66 -fold compared with sham for $\mathrm{Tnfa}^{-/-}$and WT mice, respectively; $P=\mathrm{NS}$ ). These results demonstrate that BMDC- $\alpha$ GalCer-mediated specific NKT cell activation exacerbates moderate kidney IRI inflammation through IFN- $\gamma$-dominant cytokine production.

To further investigate whether kidney injury by specific NKT cell activation is mediated by the IL-23/IL-17 pathway, we also adoptively transferred WT BMDC- $\alpha$ GalCer to $p 40^{-/-}, p 19^{-/-}$, $I l 17 \mathrm{a}^{-/-}$, and $I l 17 \mathrm{r}^{-/-}$mice (IL-23/IL-17A/R pathway) and, for comparison with the IL-12/IFN- $\gamma$ pathway, to $p 35^{-/-}$and Ifng ${ }^{-/-}$mice. Interestingly, only WT mice that received BMDC- $\alpha$ GalCer before surgery showed significant functional (Figure 6C) and morphological injury (H\&E staining; data not shown) and an anticipated infiltration of neutrophils (data not shown), including a population of GR- $1^{+}$IFN- $\gamma^{+}$neutrophils in kidney (Figure $6 \mathrm{D}$ ), following moderate kidney IRI. In addition, adoptive transfer of BMDC$\alpha \mathrm{GalCer}$ prior to surgery produced a dramatic increase in plasma IFN- $\gamma$ levels in WT mice, which was consistent with higher plasma creatinine levels following kidney IRI, compared with mice deficient in NKT cells, IL-12, IL-23, IL-17, or IFN- $\gamma$ (Figure 6E). These results suggest that both IL-12/IFN- $\gamma$ and IL-23/IL-17 signal

Table 1

IFN- $\gamma$-producing GR-1+ neutrophils in WT, $p 35^{-/-}, p 40^{--}, p 19^{--}, 1 / 17 r^{--}$, and $/ 117 a^{-1-}$ mouse kidneys

\begin{tabular}{|c|c|c|c|c|c|c|}
\hline Treatment & WT & p35-- & $p 40^{-1-}$ & $p 19-/$ & $1117 r^{\prime-}$ & $1117 a^{-/-}$ \\
\hline Sham & $0.62 \pm 0.12(5)$ & $0.32 \pm 0.06(3)$ & $0.43 \pm 0.04(2)$ & $0.17 \pm 0.09(2)$ & $0.93 \pm 0.24(5)$ & $0.28 \pm 0.11(2)$ \\
\hline$|\mathrm{R}|^{\mathrm{A}}$ & $5.67 \pm 1.28(5)$ & $0.96 \pm 0.32(5)^{\mathrm{B}}$ & $1.33 \pm 0.17(4)^{B}$ & $0.76 \pm 0.12(5)^{\mathrm{B}}$ & $1.41 \pm 0.13(2)^{B}$ & $0.99 \pm 1.27(5)^{\mathrm{B}}$ \\
\hline
\end{tabular}

Data are expressed as the number of IFN- $\gamma$-producing neutrophils in kidney $\left(\times 10^{5} / \mathrm{g}\right.$ kidney). Numbers in parentheses are $n$ values. ${ }^{A}$ Kidney ischemia for 28 minutes, followed by 24 hours of reperfusion. ${ }^{\mathrm{B}} P<0.001$ compared with WT IRI. 

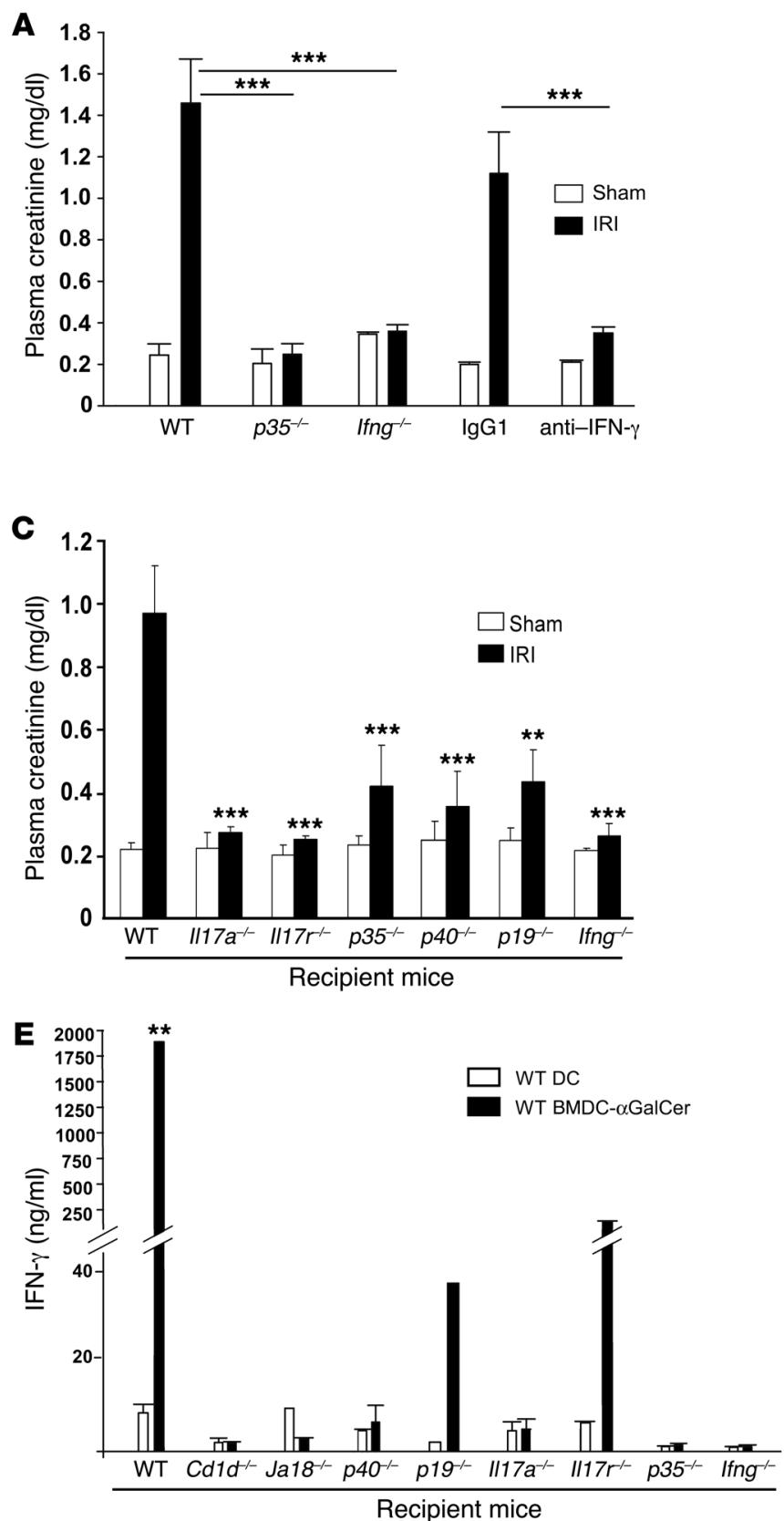

$\mathbf{B}$

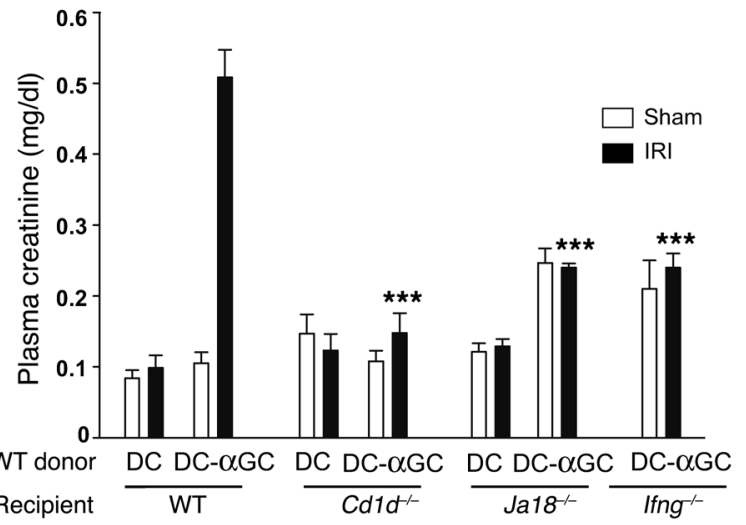

D

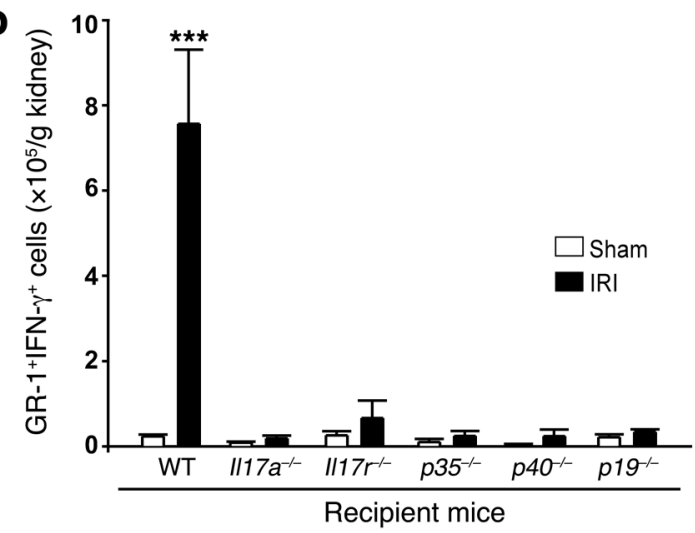

\section{Figure 6}

Both IL-12/IFN- $\gamma$ and IL-23/IL-17 pathways are necessary in activated NKT cell-promoted kidney IRI inflammation. (A-C) Plasma creatinine levels in mice 24 hours after kidney IRI. (A) Plasma creatinine levels in WT, p35-/-, and Ifng ${ }^{-1-}$ mice or in WT mice after administration of anti-IFN- $\gamma$ mAb or isotype control IgG1. $n=2-11$; ${ }^{* \star} P<0.001$. (B) Plasma creatinine levels after adoptive transfer of $6 \times 10^{5}$ unprimed DCs or BMDC$\alpha$ GalCer (DC- $\alpha \mathrm{GC})$ to NKT cell-deficient WT mice $\left(\mathrm{Cd}_{1 \mathrm{~d}^{-/-}}\right.$and $\left.\mathrm{Ja1}^{-/-}\right)$or Ifng ${ }^{-/-}$mice. BMDC-aGalCer was used to specifically activate NKT cells, which promoted moderate kidney IRI (24 minutes of ischemia) in WT mice. $n=4-12 ;{ }^{* * *} P<0.001$ compared with WT BMDC- $\alpha$ GalCer IRI. (C and D) Adoptive transfer of WT BMDC- $\alpha$ GalCer to WT or KO mice prior to sham operation or moderate (24 minutes ischemia) IRI. (C) Plasma creatinine in WT mice or mice with disrupted IL-12/IFN- $\gamma\left(p 40^{-/-}, p 35^{-/-}\right.$, Ifng $\left.{ }^{-/-}\right)$or IL-23/IL-17 pathway $\left(p 40^{-/-}, p 19^{-/-}, I / 17 a^{-/-}\right.$, II17r $\left.r^{-/}\right)$. $n=4-8 ;{ }^{* \star} P<0.01 ;{ }^{* \star} P<0.001$ compared with WT IRI. (D) The number of IFN- $\gamma$-producing GR-1+ neutrophils in the kidney was determined by FACS intracellular staining analysis in WT and IL-12/IFN- $\gamma$ KO and IL-23/IL-17A/IL-17R KO mice. $n=4-6$; ${ }^{* * \star} P<0.001$ compared with KO IRI mice. (E) Plasma IFN- $\gamma$ levels (measured by ELISA) in mice after adoptive transfer of DCs or BMDC- $\alpha$ GalCer. $n=2-7$; ${ }^{* *} P<0.01$, compared with BMDC- $\alpha$ GalCer-treated IRI KO mice. All values are mean \pm SEM.

pathways are necessary for activated NKT cell-mediated kidney inflammation, neutrophil infiltration, and neutrophil IFN- $\gamma$ production following IRI and that IL-23/IL-17 signaling regulates NKT cell IFN- $\gamma$ production.
IL-17A is upstream of IFN- $\gamma$ in the inflammatory process in kidney IRI. To further define in vivo the relationship between the IL-17 pathway and IFN- $\gamma$ in kidney IRI, an optimal dose of exogenous recombinant mouse $(\mathrm{rm})$ IL-17A $(50 \mathrm{ng})$ was administered to 


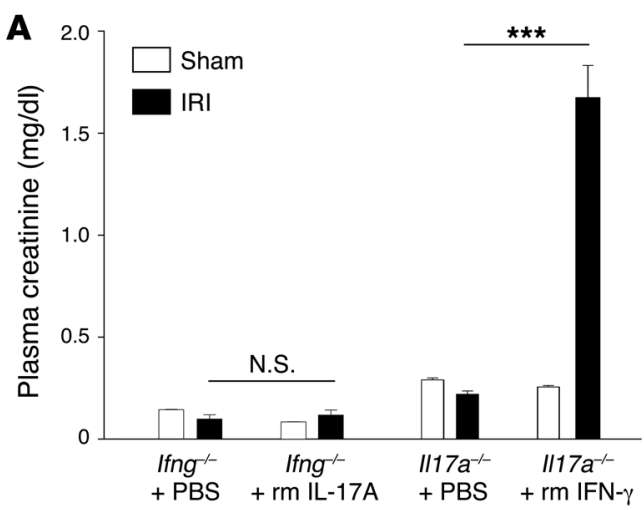

\section{Figure 7}

IL-17A is upstream of IFN- $\gamma$ production in kidney IRI. Plasma creatinine (A) and neutrophil infiltration (B) in Ifng $^{-1-}$ mice that received PBS or $50 \mathrm{ng}$ rm IL-17A 1 hour before kidney IRI or $1 / 17 a^{-/-}$mice treated with PBS (vehicle) or $30,000 \mathrm{U}$ rm IFN- $\gamma 1$ hour prior to kidney IRI or sham surgery. (A) $n=4-6$; ${ }^{* * *} P<0.001$. (B) Kidney CD11b+GR-1+ neutrophils were measured by FACS. $n=2-4$; ${ }^{*} P<0.05$. Values are mean \pm SEM.
Ifng ${ }^{-/-}$mice 1 hour prior to kidney surgery. The protection from injury observed in the control Ifng ${ }^{-/-}$mice (which received PBS) was not reconstituted by administration of rm IL-17A, as plasma creatinine did not increase in either group of mice after IRI relative to the sham groups (Figure 7A). Conversely, plasma creatinine increased significantly in $I l 17 r^{-/}$(data not shown) or $I l 17 a^{-/-}$mice that received $\mathrm{rm}$ IFN- $\gamma(30,000 \mathrm{U} /$ mouse 1 hour before IRI) compared with vehicle-treated mice (Figure 7A). Similarly, reconstitution of the infiltration of $\mathrm{CD} 11 \mathrm{~b}^{+} \mathrm{GR}-1^{+}$neutrophils after IRI was

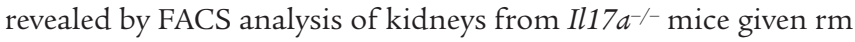
IFN- $\gamma$ but not in Ifng ${ }^{-1-}$ mice given rm IL-17A (Figure 7B). These results indicate that IL-17A is upstream of IFN- $\gamma$ in the inflammatory response that occurs in kidney IRI.

Taken together with our results described above (that mice deficient in not only $\mathrm{p} 35 / \mathrm{IFN}-\gamma$ but also the IL-23/IL-17A/R pathway showed decreased neutrophil recruitment and IFN- $\gamma$ production after IRI), these results suggest that cross-talk between the IL-12/ IFN- $\gamma$ and IL-23/IL-17 pathways promotes the cytokine cascade immune responses in kidney IRI.

\section{Discussion}

In this study we establish a critical role for both the IL-12/IFN- $\gamma$ and IL-23/IL-17 signaling pathways in mediating the innate immune response to kidney IRI and that IL-23/IL-17 is proximal to and necessary for IL-12/IFN- $\gamma$-mediated tissue injury. IL-17A produced from neutrophils regulates NKT activation, IFN- $\gamma$ production, neutrophil infiltration, and tissue injury in kidney IRI. We determined that neutrophils, and not Th17 cells, contribute to the innate immune response of kidney IRI, as we found that neutrophils are the predominant source of IL-17A that contributes to kidney IRI. We further demonstrated that IL-12/IFN- $\gamma$ and IL-23/IL-17 do not simply act in parallel, but rather activation of the IL-23/IL-17 axis is necessary for stimulating the IL-12/IFN- $\gamma$ axis to regulate neutrophil migration and a "sterile" innate immune response in a model of kidney injury (Figure 8).

Although the IL-23/Th17/IL-17 pathway has been best described in mediating chronic inflammatory diseases (3), such as rheumatoid arthritis, asthma, systemic lupus erythematosus and multiple sclerosis and in allograft rejection (13-15), little was known regarding the IL-23/IL-17 pathway in innate immunity and nothing was known regarding acute kidney IRI. Proinflammatory cytokines and chemokines are produced by stromal, epithelial, and endothelial cells in response to IL-17 to rapidly recruit neutrophils to sites of infection (13). Th17 cells differentiate from precursor cells in the presence of TGF- $\beta$ and IL- 6 (and perhaps IL-1 $\beta$ ), and IL-23 is important for maintenance and expansion of the Th17 cell population (29). These studies and the results of prior studies that demonstrated increased expression of TGF- $\beta$, IL- 6 , IL-1 $\beta$, and chemokines that mediate neutrophil infiltration after kidney IRI (30-32) suggested that Th17 cells may play a role in IL-17 production and subsequent regulation of neutrophil migration. However, the current study demonstrated a rapid increase in neutrophil influx in response to activation of IL-17/IL-23 from non-Th17 cells following kidney IRI, suggesting that acute innate mechanisms were responsible for the observed injury. This conclusion was supported by the absence of $\mathrm{T}$ and $\mathrm{B}$ cell production of IL-17. In contrast, we showed that neutrophils produce IL-17A following kidney IRI and that these cells contribute to the inflammatory response to kidney injury. First, as early as 3 hours following kidney IRI, we found more IL-17A-producing CD $45^{+}$cells in the kidney. Second, we demonstrated that bone marrow-derived cells that produce IL-17A are necessary for kidney injury. We drew this conclusion from studies in which we showed that $I l 17 a^{-/-} \rightarrow$ WT bone marrow chimeras had significantly less neutrophil infiltration and tissue injury 24 hours after kidney IRI compared with WT $\rightarrow$ WT chimeras. Third, we demonstrated that the IL-17-producing cells in kidney IRI are not $\mathrm{T}$ cells or B cells. Kidneys from Rag $1^{-/-}$mice, which lack $\mathrm{T}$ cells and B cells, were protected from kidney IRI after IL-17A neutralization. Fourth, the IL-17A-secreting cells detected in kidneys after 3 hours of reperfusion were CD $11 b^{+} \mathrm{GR}-1^{+}$neutrophils. Fifth, the protection in $I l 17 a^{-/-}$mice was reversed following adoptive transfer of WT neutrophils but not $I l 17 \mathrm{a}^{-/-}$neutrophils, and the reconstituted injury was attenuated by antibody neutralization of IL-17A. Taken together, these data demonstrate that IL-17A-producing neutrophils contribute to innate immunity in kidney IRI. A previous report of neutrophil production of IL-17 was limited to RT-PCR of $I l 17$ mRNA from a relatively pure population of neutrophils (33). High levels of IL-23 that are produced early in kidney tissue after IRI may promote neutrophil IL-17A production. Thus a "feed-forward" system may have evolved in which the initial stimulus of neutrophil influx may be further augmented in a second wave due in part to neutrophil production of IL-17A acting in an autocrine fashion and producing the neutrophil chemoattractants CXCL1 and -2 (Figure 3F).

Our previous study showed that IRI activated the Th1 pathway through activation of NKT cells (20). In that study we identified a large influx of NKT cells that produced IFN- $\gamma$ within 3 hours of reperfusion after ischemia, and through the use of $\mathrm{Ja} 18^{-/-}$and $C d 1 d^{-/-}$mice and monoclonal antibodies to block the interac- 

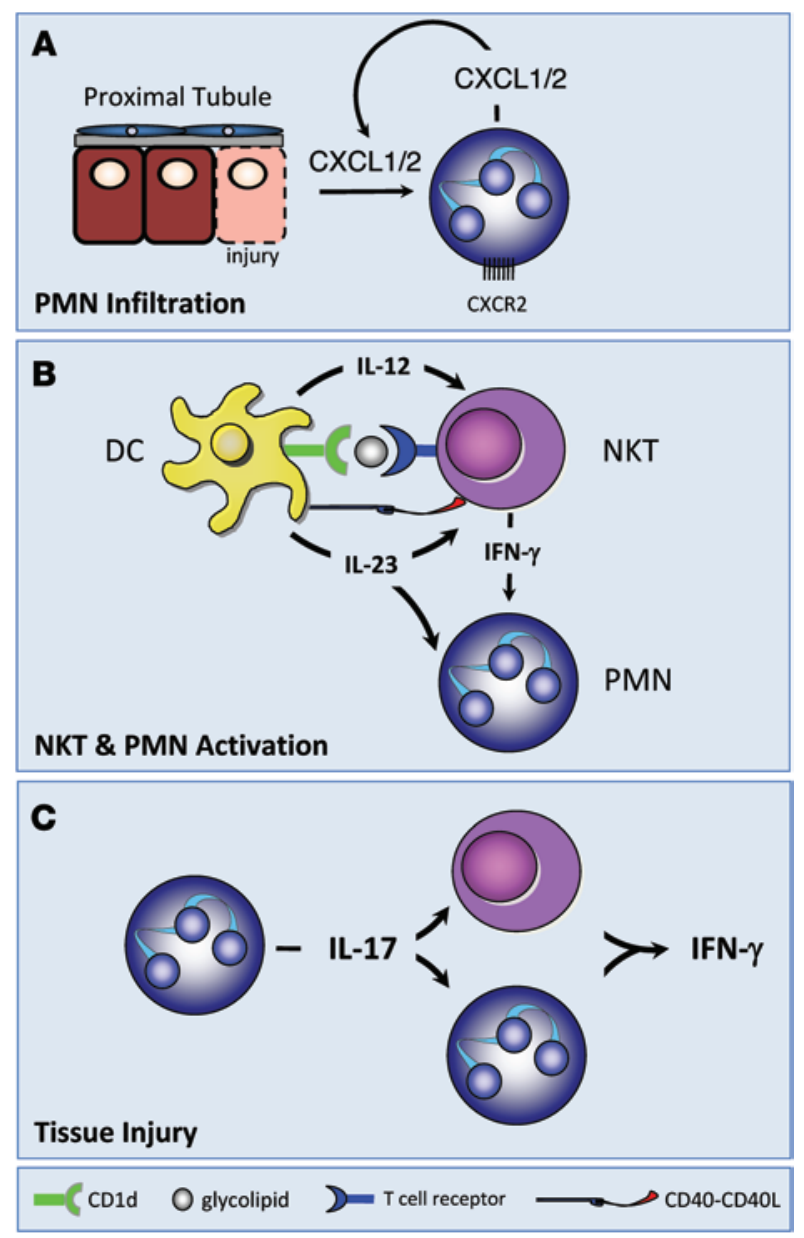

tion between CD1d-glycolipid presentation to NKT cells (CD1d $\mathrm{mAb}$ ), we demonstrated the functional importance of NKT cells in the innate immune response to kidney IRI (20). IFN- $\gamma$ was produced mainly from CD1d-restricted NKT cells and GR-1 ${ }^{+}$ neutrophils in kidney after IRI (20). CD $4^{+} \mathrm{NKT}$ cells may provide an explanation for how $\mathrm{T}$ cells, traditionally a part of the adaptive immune system, play a role in innate immunity. The results of the current study also demonstrate that the IL-23/IL-17 signal pathway regulates IL-12/IFN- $\gamma$, driving neutrophil migration and tissue injury. IL-12 and IL-23 are produced by DCs (22), the major leukocyte subset in kidney ( $50 \%)(22)$. In addition to activation of the IL-23/IL-17 signaling pathway, we also established that this pathway regulates IL-12/IFN- $\gamma$ in mediating tissue injury. In the current study, adoptive transfer of BMDC$\alpha$ GalCer exacerbated the inflammatory response to moderate kidney IRI by activating NKT cells and stimulating secretion of a large amount of IFN- $\gamma(20)$. This effect was blocked with anti-p40 neutralization $\mathrm{mAb}$ (our unpublished observations). Adoptive transfer of BMDC- $\alpha$ GalCer to activate NKT cells prior to surgery did not enhance kidney injury in p35/p40/IFN- $\gamma$ signal-deficient or $\mathrm{p} 40 / \mathrm{p} 19 / \mathrm{IL}-17$ signal-deficient mice compared with WT mice after a subthreshold ischemic injury. In addition, BMDC- $\alpha$ GalCer-triggered effector cytokine IFN- $\gamma$ production from GR-1 $1^{+}$neutrophils was dependent not only on p35/IFN- $\gamma$ signaling, but also on $\mathrm{p} 40 / \mathrm{p} 19 / \mathrm{IL}-17$ signaling. These data demonstrate that the absence of either IL-12/IFN- $\gamma$ or IL-23/IL-17

\section{Figure 8}

Model summarizing the role of the IL-12/IFN- $\gamma$ and IL-23/IL-17 axes of the innate immune response in kidney IRI. (A) Injury to kidney epithelial cells early ( 6 hours) following IRI promotes inflammation by increasing pro-inflammatory cytokine/chemokine production, including neutrophil chemoattractant chemokines (CXCL1 and CXCL2). CXCL1 and CXCL2 mediate PMN recruitment and kidney injury through the chemokine receptor CXCR2 (expressed mainly on neutrophils). Autocrine CXCL1/2 production by infiltrating PMNs likely stimulates additional infiltration. (B) Both IL-12/IFN- $\gamma$ and IL-23/IL-17 pathways are activated in kidney IRI. Kidney resident DCs initiate the immune response following kidney IRI by secreting IL-12 and IL-23. DCs activate NKT cells by CD1d-mediated glycolipid presentation and CD40/CD40L costimulation. IL-12 mediates NKT cell activation and IFN- $\gamma$ production, which further stimulates neutrophil IFN- $\gamma$ production and infiltration of PMNs and other immune cells (CD4 ${ }^{+}$and NKT cells and macrophages; not shown) that contribute to kidney injury. IL-23 is also involved in NKT cell activation (our unpublished observations). IL-23 (with TGF- $\beta$ and IL-6; not shown) is known to induce Th17 cell differentiation, but neutrophils, not Th17 cells, are the predominant source of IL-17A in the innate immune response in kidney IRI. IL-23 and its downstream cytokine IL-17A induce pro-inflammatory cytokine (IL-6, IL-1 $\beta$, TNF- $\alpha$ ) and chemokine (CXCL1/2) (not shown) production to promote kidney inflammation. (C) The IL-23/IL-17 axis is proximal to and necessary for IL-12/IFN- $\gamma$-mediated tissue injury through NKT cell activation. IL-17A produced from PMNs regulates NKT cell activation, IFN- $\gamma$ production, $\mathrm{PMN}$ infiltration and tissue injury in kidney IRI. Therefore, in addition to IL-12/IFN- $\gamma$, IL-23 and IL-17 signal pathways also participate in the innate immune response to IRI by stimulating activated NKT cell-mediated kidney inflammation and PMN infiltration.

signaling blocked the enhancement of injury typically mediated by rapid, early NKT cell activation. Furthermore, less IFN- $\gamma$

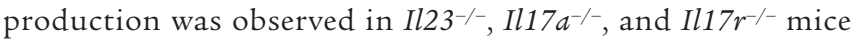
following BMDC- $\alpha$ GalCer stimulation. This suggests that the IL-23/IL-17 axis is a critical pathway that is necessary for IFN- $\gamma$ secretion in the acute innate immune response of kidney IRI. Moreover, rm IFN- $\gamma$ administered to $I l 17 a^{-/-}$mice subjected to IRI reversed the protection normally seen in $I l 17 a^{-/-}$mice, thereby resulting in impaired kidney function and enhanced neutrophil migration, whereas rm IL-17A did not reverse the protective effect of IFN- $\gamma$ deficiency following kidney IRI. Taken together, the data here demonstrate that the IL-17A/R signal is upstream of IFN- $\gamma$ in the mediation of inflammation and neutrophil infiltration in kidney IRI.

Cells producing both IFN- $\gamma$ and IL-17 are uncommon but have been reported in human intestine with inflammatory bowel disease (34), and these double-positive cells in a mouse EAE model co-expressed ROR $\gamma$ t and T-bet (35); the biological importance of this unique cell population is unclear. In another example of alternate pathways, IL-23 promoted IFN- $\gamma$ production, rather than IL-17 production, via an IL-23- and TNF- $\alpha$-dependent pathway in human colon disease (36). These findings and our current results indicate that IL-23 is involved in the pathogenesis of disease not only through IL-23/IL-17, but also through a previously undefined IL-23/IFN- $\gamma$ axis. Together with our previous data (20), we found that neutrophils produce both IFN- $\gamma$ and IL-17A in kidney. The autocrine effect of IL-17A on neutrophil IFN- $\gamma$ production and the role of the transcription factors ROR $\gamma t$ and T-bet in neutrophils will require further investigation.

Macrophages are recruited in a CCR2- and CX3CR1-dependent manner to the inflamed kidney (22). IL- 1 and IL- 6 are produced in the kidney following IRI (19), mainly by infiltrating macrophages 
(22). Considering the requirement of IL-1 and IL-6 for IL-17A production, these results suggest that IL- 1 and IL- 6 act upstream of IL-17A to induce kidney IRI inflammation. We have shown that kidneys of mice deficient in IL- 6 were protected from IRI and had reduced neutrophil infiltration (our unpublished observations). These findings suggest that macrophages contribute to neutrophil recruitment and cytokine/chemokine production and may be involved in the IL-12/IFN- $\gamma$ and IL-23/IL-17 axes in kidney IRI. Further investigation of the role of macrophage-derived cytokines and the relationship of the IL-12/IFN- $\gamma$ and IL-23/IL-17 pathways to trafficking of heterogeneous macrophage subpopulations in the inflamed kidney is needed.

Collectively, our study demonstrated that both IL-12 and IL-23 and their subsequent IFN- $\gamma /$ IL-17 signaling pathways participated in the innate immune inflammation associated with kidney IRI. Our data also supported the requirement of IL-17A in regulating IFN- $\gamma$ in the innate immune response to injury. Both IL-17A and IFN- $\gamma$ are produced by neutrophils and may positively regulate neutrophil transmigration to the injured kidney following kidney IRI. Further identification of the mechanism of IL-17 and IFN- $\gamma$ release from neutrophils will add to our understanding of the immunological pathways involved in kidney IRI and should aid in development of new therapeutic strategies for patients with acute kidney injury. Whether the IL-23/IL-17 pathway contributes to reperfusion injury of other organs such as heart, lung, and brain will need to be established, and a clear understanding of this pathway may yield important targets for therapy.

\section{Methods}

Mice and surgical protocol. All experiments were performed in accordance with NIH and IACUC guidelines. The Animal Research Committee of the University of Virginia approved all procedures and protocols. We used WT C57BL/6 mice ( 20 g, 6-8 weeks old; Charles River Laboratories), and the following genetically deficient mice were bred on a C57BL/ 6 background: p19-/- (a gift from Dan Cua, Schering-Plough Biopharma), Il17 $a^{-/-}$(a gift from Yoichiro Iwakura, University of Tokyo, Tokyo, Japan), and Ill17r-/(Amgen Inc.). $p 40^{-/-}, p 35^{-/}$, and Ifng ${ }^{-/-}$mice on a C57BL/ 6 background were purchased from The Jackson Laboratory.

Following anesthesia, bilateral flank incisions were performed as previously described (19). Both kidney pedicles were exposed and cross-clamped for 28 minutes, then clamps were released (reperfusion) for different times. In experiments designed to evaluate exacerbation of injury, kidneys were clamped for only 24 minutes to produce moderate injury. Body temperature was maintained at $37^{\circ} \mathrm{C}$ during surgery. Kidney pedicles were exposed but not clamped in sham-operated mice.

Varying doses of previously described (4) monoclonal anti-mouse IL-17A (clone 50104; R\&D Systems), p19 (G23-8), and IFN- $\gamma$ (XMG1.2; eBioscience) were evaluated (Supplemental Figure 3), and the optimal dose of these neutralization antibodies $(100 \mu \mathrm{g} /$ mouse for anti-p19 and anti-IFN- $\gamma ; 50 \mu \mathrm{g} /$ mouse for anti-IL-17A) or their respective isotype controls was administrated i.v. 18 hours prior to kidney surgery. Anti-CXCR2 goat serum or control goat serum was administered i.v. to WT mice 18 hours and 1 hour prior to kidney surgery (37). In some experiments mice received rm IL-17A (50 ng i.p.; R\&D System) or IFN- $\gamma$ (30,000 U i.p.; PeproTech) 1 hour prior to ischemia.

Real-time PCR. Total RNA was extracted from kidneys with Tri Reagent according to the manufacturer's protocol (Molecular Research Center Inc.). Gene sequences were obtained from the GenBank database. Primers were designed using IDT PrimerQuest (http://www.idtdna.com/ Scitools/Applications/Primerquest/; Integrated DNA Technologies) and Primer 3 (http://frodo.wi.mit.edu/primer3/). Primer sequences were as follows: p40, ACCTGTGACACGCCTGAAGAAGAT (forward), TCTTGTGGAGCAGCAGATGTGAGT (reverse); p19, CAACTTCACACCTCCCTAC (forward), CCACTGCTGACTAGAACT (reverse); CXCL1, TGGCTGGGATTCACCTCAAGAACA (forward), TGTGGCTATGACTTCGGTTTGGGT (reverse); CXCL2, ACATCCCACCCACACAGTGAAAGA (forward), ACATCCCACCCACACAGTGAAAGA (reverse); IL-6, TGGCTAAGGACCAAGACCATCCAA (forward), AACGCACTAGGTTTGCCGAGTAGA (reverse); TNF- $\alpha$, CCTCCCTCTCATCAGTTCTATGG (forward), CGTGGGCTACAGGCTTGTC (reverse); and GAPDH, ACGGCAAATTCAACGGCACAGTCA (forward), TGGGGGCATCGGCAGAAGG (reverse). RT-PCR was performed on the cDNA using the iScript 1-step RT-PCR kit with SYBR Green (Bio-Rad), and samples were normalized to GAPDH. All real-time PCR assays were performed in duplicate $25-\mu 1$ reactions in 96 -well plates. The resulting melting curves were visually inspected to ensure specificity of product detection. The following PCR protocol was used: initial denaturation $\left(95^{\circ} \mathrm{C}\right.$ for 3 minutes); denaturation, annealing, and elongation program repeated 35 times $\left(95^{\circ} \mathrm{C}\right.$ for 45 seconds, $52^{\circ} \mathrm{C}$ for 60 seconds, and $72^{\circ} \mathrm{C}$ for 60 seconds); final elongation $\left(72^{\circ} \mathrm{C}\right.$ for 7 minutes); and finally, a holding step at $4^{\circ} \mathrm{C}$ as described previously (38).

Tissue digestion and kidney neutrophil cell counting by FACS. Kidney cell suspensions were prepared from mice subjected to IRI or sham operation, and kidney leukocyte subset cell number was calculated as described before (20). Kidney $\mathrm{CD} 45^{+} \mathrm{CD} 11 \mathrm{~b}^{+} \mathrm{GR}-1^{+} 7-\mathrm{AAD}^{-}$cells were identified as neutrophils. The following antibodies $(1 \mu \mathrm{g} / \mathrm{ml}$; eBioscience) were used to identify kidney neutrophils: APC-conjugated Alexa Fluor 750-labeled anti-mouse CD45 (30-F11), PE-labeled anti-mouse CD11b (M1/70), and APC-labeled anti-mouse GR-1 (Ly6G RB6-8C5). 7-AAD was used to exclude dead cells. Flow cytometry data were acquired using BD FACSCalibur (BD Biosciences) and analyzed with FlowJo software 6.4 (Tree Star Inc.).

Measurement of kidney IL-17A-producing leukocytes. Sham and IRI mouse kidneys were digested after different periods of reperfusion, and CD45+ cells were isolated using anti-CD45 microbeads (Miltenyi Biotec Inc.). Isolated $\mathrm{CD} 45^{+}$cells were restimulated with a leukocyte activation cocktail (with BD GolgiPlug) for 5 hours following the manufacturer's protocol (BD Biosciences). Intracellular staining of IL-17A and analysis by FACS was performed as previously described (20). PE-labeled anti-mouse IL-17A (TC11-18H10; BD Biosciences) and APC-Alexa Fluor 750-labeled CD45 (30-F11; eBioscience) were added to each sample separately after blocking with anti-mouse CD16/32 (1 $\mu \mathrm{g} / \mathrm{ml}$; eBioscience) for $20 \mathrm{~min}$ utes on ice. Intracellular isotype controls were performed at the same time. 7-AAD was used to exclude dead cells.

Intracellular IFN- $\gamma$ detection was performed by FACS as described before (20). The cell surface was labeled with anti-mouse GR-1, then cells were washed, fixed, permeabilized, and labeled with anti-mouse IFN- $\gamma$ ( $1 \mu \mathrm{g} / \mathrm{ml}$; eBioscience).

Detection of IL-17A-secreting cells. The protocol provided by Miltenyi Biotec was followed. Mouse kidneys were digested and cell pellets were stimulated in vitro with phorbol myristate acetate $(10 \mathrm{ng} / \mathrm{ml})$ and ionomycin $(1 \mu \mathrm{g} / \mathrm{ml})$ for 3 hours. Cells were washed and labeled with IL-17 Catch reagent (Miltenyi Biotec) for 5 minutes on ice. Warm complete RPMI-1640 medium was added, and cells were incubated for 45 minutes at $37^{\circ} \mathrm{C}$. After washing, cells were incubated with biotinylated anti-mouse IL-17 detection antibody for 10 minutes on ice. Cells were washed, and PE-labeled anti-biotin and additional staining reagents such as GR-1(Ly6G)-FITC, CD45-APC-Alexa Fluor 750, CD11b-APC, and 7-AAD or fluorophoretagged antibodies against markers for T cells (CD4 and CD8) and NK cells (NK1.1) were added at the same time for 10 minutes on ice. Cells were washed, and data were collected using FACS. 
Priming BMDCs with $\alpha$ GalCer. Bone marrow cells were isolated from WT mice, and $98 \%$ pure DCs were obtained following 2 weeks in culture as described before (39). Cells were primed with $1 \mu \mathrm{g} / \mathrm{ml} \alpha$ GalCer (AXXORA LLC) for 2.5 days, and vehicle ( $0.1 \%$ DMSO in culture medium) was used as a control. Primed or unprimed cells were washed, and $0.6 \times 10^{6} \mathrm{cells} / \mathrm{mouse}$ (optimal dose) were introduced i.v. to naive mice for 2 days prior to kidney ischemia-reperfusion surgery and a moderate (24-minute) ischemic injury.

Bone marrow polymorphonuclear cell isolation and adoptive transfer. Bone marrow polymorphonuclear cells (PMNs) were collected using Percoll gradients as described before (40), and the purity was assessed by FACS. More than $96 \%$ CD $11 b^{+}$GR-1(Ly6G) $)^{+}$PMNs were collected. WT or $I l 17 a^{-1-}$ PMNs $\left(10^{6}\right)$ were adoptively transferred to naive $I l 17 a^{-/-}$mice 1 hour prior to ischemia-reperfusion surgery.

Generation of chimeric mice. Chimeric mice were generated by transferring bone marrow cells as described before (19). There were 2 groups of bone

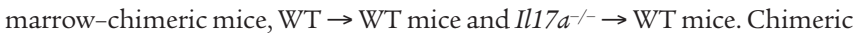
mice were used 8 weeks after bone marrow transfer. Using this method, reconstitution efficiency was nearly $95 \%(19,41)$.

Histochemistry. Kidneys were fixed for $\mathrm{H} \& \mathrm{E}$ staining as previously described (41) and viewed by light microscopy (Zeiss AxioSkop) under $\times 200$ magnification. Photographs were taken and brightness/contrast adjustment was made with a SPOT RT camera (software version 3.3; Diagnostic Instruments). Histological examinations were performed by 2 renal pathologists blinded to the conditions. The histological change in the outer medulla was expressed as ATN, scored by counting the percentage of tubules that displayed cell necrosis, loss of brush border, cast formation, and tubule dilatation as follows: 0 , none; $1,<10 \% ; 2,11 \%-25 \% ; 3,26 \%-45 \%$; 4, 46\%-75\%; and 5, >76\%. At least 5-10 fields ( $\times 200$ magnification) were reviewed for each slide (42).

Immunofluorescence and optical sectioning microscopy. Kidneys from mice were fixed in $1 \%$ PLP (1\% paraformaldehyde, $1.4 \%$ DL-lysine, $0.2 \%$ sodium periodate in $0.1 \mathrm{M}$ PBS, pH 7.4) (22) overnight, incubated in $30 \%$ sucrose for 48 hours at $4{ }^{\circ} \mathrm{C}$, and embedded and frozen in OCT (Ted Pella Inc.). Frozen sections $(10 \mu \mathrm{m})$ were permeabilized with $0.3 \%$ Triton X-100, and nonspecific binding was blocked with $10 \%$ donkey serum and anti-mouse
CD16/32 (10 $\mu \mathrm{g} / \mathrm{ml}$; clone 2.4G2; StemCell Technologies Inc.). Sections were labeled with rabbit anti-mouse CXCL1 (KC) antibody $(2.5 \mu \mathrm{g} / \mathrm{ml}$; PeproTech Inc.) for 1 hour at room temperature. After washing, samples were incubated with Cy3-conjugated donkey anti-rabbit antibody (1:500; Jackson ImmunoResearch Laboratories Inc.) and FITC-labeled anti-neutrophil monoclonal antibody ( $7 \mu \mathrm{g} / \mathrm{ml}$; clone 7.4; Abcam) for 1 hour. All specimens were mounted with ProLong Gold Antifade reagent with DAPI (Invitrogen). Images were acquired using the Zeiss Axiovert 200 microscopy system with ApoTome imaging (Carl Zeiss). Image processing was achieved using Zeiss AxioVision 4.6 software, and composite panoramic images were obtained by manually stitching adjacent overlapping images together using Adobe Photoshop (Adobe).

Statistics. GraphPad Instat 3 (GraphPad Inc.), SigmaPlot 11.0 (Systat Software Inc.), and Canvas X (ACD Systems of America Inc.) were used to analyze and present the data. Data were analyzed, after transformation if needed to generate a normal distribution, by 2-tailed $t$ test or 1- or 2-way ANOVA with post-hoc analysis as appropriate. $P<0.05$ was used to indicate significance.

\section{Acknowledgments}

This work was supported in part by funds from NIH grants RO1DK56223, RO1DK62324, and P01HL073361; the Genzyme Renal Innovations Program; and the American Heart Association National Scientist Development Grant 0835258N. We thank Peter I. Lobo, Sung-Sang Sung, Gilbert Kinsey, and David Becker of the University of Virginia for providing advice and help during the course of the studies. We also thank the University of Virginia Research Histology Core.

Received for publication August 28, 2009, and accepted in revised form October 21, 2009.

Address correspondence to: Li Li, Division of Nephrology, Box 800133, University of Virginia Health System, Charlottesville, Virginia 22908, USA. Phone: (434) 924-2110; Fax: (434) 924-5848; E-mail:113m@virginia.edu.
1. Sun J, et al. TLR ligands can activate dendritic cells to provide a MyD88-dependent negative signal for Th2 cell development. J Immunol. 2005;174(2):742-751.

2. Re F, Strominger JL. Heterogeneity of TLR-induced responses in dendritic cells: from innate to adaptive immunity. Immunobiology. 2004;209(1-2):191-198

3. Langrish CL, et al. IL-23 drives a pathogenic T cell population that induces autoimmune inflammation. J Exp Med. 2005;201(2):233-240.

4. Kroenke MA, Carlson TJ, Andjelkovic AV, Segal BM. IL-12- and IL-23-modulated T cells induce distinct types of EAE based on histology, CNS chemokine profile, and response to cytokine inhibition. J Exp Med. 2008;205(7):1535-1541.

5. McGeachy MJ, Cua DJ. Th17 cell differentiation: the long and winding road. Immunity. 2008;28(4):445-453.

6. Dong C. TH17 cells in development: an updated view of their molecular identity and genetic programming. Nat Rev Immunol. 2008;8(5):337-348.

7. Lai Kwan Lam Q, King Hung Ko O, Zheng BJ, Lu L. Local BAFF gene silencing suppresses Th17-cell generation and ameliorates autoimmune arthritis. Proc Natl Acad Sci U S A. 2008;105(39):14993-14998.

8. Maloy KJ. The Interleukin-23 / Interleukin-17 axis in intestinal inflammation. J Intern Med. 2008;263(6):584-590

9. Ogura $\mathrm{H}$, et al. Interleukin-17 promotes autoimmunity by triggering a positive-feedback loop via interleukin- 6 induction. Immunity.
2008;29(4):628-636

10. Stark MA, Huo Y, Burcin TL, Morris MA, Olson TS, Ley K. Phagocytosis of apoptotic neutrophils regulates granulopoiesis via IL-23 and IL-17. Immunity. 2005;22(3):285-294.

11. Ley K, Smith E, Stark MA. IL-17A-producing neutrophil-regulatory Tn lymphocytes. Immunol Res. 2006;34(3):229-242.

12. von Vietinghoff S, Ley K. Homeostatic regulation of blood neutrophil counts. J Immunol. 2008;181(8):5183-5188.

13. Kolls JK, Linden A. Interleukin-17 family members and inflammation. Immunity. 2004;21(4):467-476.

14. Moseley TA, Haudenschild DR, Rose L, Reddi AH. Interleukin-17 family and IL-17 receptors. Cytokine Growth Factor Rev. 2003;14(2):155-174.

15. Aggarwal S, Gurney AL. IL-17: prototype member of an emerging cytokine family. J Leukoc Biol. 2002;71(1):1-8

16. Smits HH, et al. Commensal Gram-negative bacteria prime human dendritic cells for enhanced IL-23 and IL-27 expression and enhanced Th1 development. Eur J Immunol. 2004;34(5):1371-1380.

17. Jefford M, et al. Functional comparison of DCs generated in vivo with Flt3 ligand or in vitro from blood monocytes: differential regulation of function by specific classes of physiologic stimuli. Blood. 2003;102(5):1753-1763.

18. Happel KI, et al. Cutting edge: roles of Toll-like receptor 4 and IL-23 in IL-17 expression in response to Klebsiella pneumoniae infection. J Immunol.
2003;170(9):4432-4436.

19. Day YJ, et al. Renal protection from ischemia mediated by $\mathrm{A} 2 \mathrm{~A}$ adenosine receptors on bone marrowderived cells. J Clin Invest. 2003;112(6):883-891.

20. Li L, et al. NKT cell activation mediates neutrophil IFN-gamma production and renal ischemia-reperfusion injury. J Immunol. 2007;178(9):5899-5911.

21. Huang Y, Rabb H, Womer KL. Ischemia-reperfusion and immediate $\mathrm{T}$ cell responses. Cell Immunol. 2007;248(1):4-11.

22. $\mathrm{Li} \mathrm{L}$, et al. The chemokine receptors CCR2 and CX3CR1 mediate monocyte/macrophage trafficking in kidney ischemia-reperfusion injury. Kidney Int. 2008;74(12):1526-1537.

23. Fujii S, et al. Glycolipid alpha-C-galactosylceramide is a distinct inducer of dendritic cell function during innate and adaptive immune responses of mice. Proc Natl Acad Sci US A. 2006;103(30):11252-11257.

24. Fujii S, Shimizu K, Steinman RM, Dhodapkar MV. Detection and activation of human Valpha24+ natural killer $\mathrm{T}$ cells using alpha-galactosyl ceramide-pulsed dendritic cells. J Immunol Methods. 2003;272(1-2):147-159.

25. Maeda M, et al. IL-21 enhances dendritic cell ability to induce interferon-gamma production by natural killer T cells. Immunobiology. 2007;212(7):537-547.

26. Sharif S, et al. Activation of natural killer T cells by alpha-galactosylceramide treatment prevents the onset and recurrence of autoimmune Type 1 diabetes. Nat Med. 2001;7(9):1057-1062. 
27. Nagaraj S, et al. Dendritic cells pulsed with alphagalactosylceramide induce anti-tumor immunity against pancreatic cancer in vivo. Int Immunol. 2006;18(8):1279-1283.

28. Chang YJ, et al. Potent immune-modulating and anticancer effects of NKT cell stimulatory glycolipids. Proc Natl Acad Sci U S A. 2007;104(25):10299-10304.

29. Zhou L, Chong MM, Littman DR. Plasticity of CD4+ $\mathrm{T}$ cell lineage differentiation. Immunity. 2009;30(5):646-655.

30. Haq M, Norman J, Saba SR, Ramirez G, Rabb H. Role of IL-1 in renal ischemic reperfusion injury. J Am Soc Nephrol. 1998;9(4):614-619.

31. Savransky V, et al. Role of the T-cell receptor in kidney ischemia-reperfusion injury. Kidney Int. 2006;69(2):233-238.

32. Kinsey GR, Li L, Okusa MD. Inflammation in acute kidney injury. Nephron Exp Nephrol. 2008;109(4):e102-e107.

33. Ferretti S, Bonneau O, Dubois GR, Jones CE, Trifilieff A. IL-17, produced by lymphocytes and neutrophils, is necessary for lipopolysaccharideinduced airway neutrophilia: IL-15 as a possible trigger. J Immunol. 2003;170(4):2106-2112.

34. Andoh A, et al. Cooperation of interleukin-17 and interferon-gamma on chemokine secretion in human fetal intestinal epithelial cells. Clin Exp Immunol. 2001;125(1):56-63.

35. Momcilovic M, Miljkovic Z, Popadic D, Miljkovic D, Mostarica-Stojkovic M. Kinetics of IFNgamma and IL-17 expression and production in active experimental autoimmune encephalomyelitis in Dark Agouti rats. Neurosci Lett. 2008;447(2-3):148-152.

36. Lee S, French MA, Price P. IL-23 and IFN-gamma deficiency in immunodeficient HIV patients who achieved a long-term increase in CD4 T-cell counts on highly active antiretroviral therapy. AIDS 2004;18(9):1337-1340

37. Mehrad B, et al. CXC chemokine receptor-2 ligands are necessary components of neutrophil-mediated host defense in invasive pulmonary aspergillosis. J Immunol. 1999;163(11):6086-6094.
38. Awad AS, et al. Activation of adenosine 2 A receptors preserves structure and function of podocytes. J Am Soc Nephrol. 2008;19(1):59-68.

39. Lutz MB, et al. An advanced culture method for generating large quantities of highly pure dendritic cells from mouse bone marrow. J Immunol Methods. 1999;223(1):77-92

40. Itou T, Collins LV, Thoren FB, Dahlgren C, Karlsson $\mathrm{A}$. Changes in activation states of murine polymorphonuclear leukocytes (PMN) during inflammation: a comparison of bone marrow and peritoneal exudate PMN. Clin Vaccine Immunol. 2006;13(5):575-583.

41. Day YJ, Huang L, Ye H, Li L, Linden J, Okusa MD. Renal ischemia-reperfusion injury and adenosine $2 \mathrm{~A}$ receptor-mediated tissue protection: the role of CD4+ T cells and IFN-gamma. J Immunol. 2006;176(5):3108-3114.

42. Oh DJ, et al. Fractalkine receptor (CX3CR1) inhibition is protective against ischemic acute renal failure in mice. Am J Physiol Renal Physiol. 2008;294(1):F264-F271. 